\title{
A CRÍTICA À CIÊNCIA MODERNA E UM CAMINHO PARA O DIÁLOGO EM TEMPOS DE PÓS-VERDADE
}

\author{
CRITICISM OF MODERN SCIENCE AND A PATH TO DIALOGUE IN POST- \\ TRUTH TIMES
}

\begin{abstract}
Dilian Veiga Vinhas Mestranda em Desenvolvimento Humano, Universidade de Taubaté - UNITAU São José dos Campos, São Paulo - Brasil lilian.vinhas@inpe.br

Maria Angela Boccara de Paula Doutora em Enfermagem, Universidade de São Paulo - USP Taubaté, São Paulo - Brasil boccaradepaula@gmail.com
\end{abstract}

Resumo: Neste artigo, apresenta-se a questão da crítica à ciência moderna, articulando-a com o fenômeno da pósverdade, por meio de uma revisão narrativa da literatura. Inicialmente, um breve histórico recorda o surgimento da ciência moderna, e apresentam-se duas críticas a seu respeito: a fragmentação dos saberes e o mito da objetividade científica. Delineia-se, então, o cenário atual que caracteriza a pós-verdade e, finalmente, reflete-se sobre a comunicação pública da ciência e a educação, nesse contexto, com base nas críticas à ciência apresentadas.

Palavras-chave: Ciência moderna. Pós-verdade. Educação. Comunicação pública da ciência.

Abstract: This article presents the issue of criticism of modern science, articulating it with the phenomenon of posttruth, through a narrative review of the related literature. Initially it is drawn a brief history report that revisits the outcome of the modern science, presenting two criticisms about it, the fragmentation of knowledge and the myth of scientific objectivity. Then, it outlines a new scenario that characterizes the post-truth and, finally, it reflects on the public communication of science and on education in this context, based on the criticisms on science presented in the article.

Keywords: Modern science. Post-truth. Education. Public communication of science.

\section{Para citar - ABNT NBR 6023:2018}

VINHAS, Lilian Veiga; PAULA, Maria Angela Boccara de. A crítica à ciência moderna e um caminho para o diálogo em tempos de pós-verdade. Cadernos de Pós-graduação, São Paulo, v. 19, n. 2, p. 253-265, jul./dez. 2020. Disponível em: https://doi.org/10.5585/cpg.v19n2.18373. 


\section{Introdução}

Os tempos atuais são marcados pelo que se chama de 'pós-verdade', fenômeno relacionado às fake news e ao negacionismo científico, mas também à abertura de uma comunicação mais ampla e democrática entre as pessoas.

Por meio de revisão narrativa da literatura, apresenta-se uma discussão acerca da comunicação da ciência e da educação no cenário da pós-verdade. A reflexão tem base em duas críticas à ciência moderna, o mito da objetividade e a fragmentação dos saberes, na visão de Edgar Morin e Boaventura de Sousa Santos.

Inicialmente, com um breve e ilustrativo histórico acerca do surgimento da ciência moderna, busca-se contextualizar a discussão. Apresentam-se, então, as críticas dos autores e o exemplo extraído de uma obra de Stephen Jay Gould. O olhar de Viviane Mosé sobre a pós-verdade contribui para o entendimento do fenômeno contemporâneo. Finalmente, reflete-se sobre como a comunicação pública da ciência e uma educação de caráter transdisciplinar podem contribuir para orientar os sujeitos que transitam por diferentes versões da realidade em um mundo cada vez mais plural. Sinaliza-se, então, um caminho para a reconstrução do diálogo entre ciência e sociedade, com base nas reflexões apresentadas.

\section{Breve histórico da ciência moderna}

O nascimento da denominada ciência moderna caracterizou-se, em grande medida, pela separação da 'filosofia natural' - a ciência experimental que emergia na Europa entre os séculos 16 e 17 - de outras formas de filosofia e conhecimentos humanísticos (MALET, 2002). Tratou-se de um processo coletivo, decorrente da confluência de fatores culturais, políticos, econômicos e religiosos, e não da atuação de uma ou outra figura em particular (MARICONDA, 2006). Pode-se afirmar, entretanto, que uma das bases da mudança no caráter da ciência deu-se com a proposição de Nicolau Copérnico (1473-1543), de que a Terra se move ao redor do Sol, e não o inverso, questionando assim, o modelo de Aristóteles, adotado pela Igreja, que detinha a primazia do conhecimento acadêmico (HARMAN, 1995).

A Igreja mantinha nas universidades a tradição científica aristotélica, de caráter metafísico, unida à teologia e conduzida de maneira puramente teórica, sem interesse em aplicações práticas. Fora desse meio, nas escolas de artistas e nos arsenais desenvolvia-se o ensino técnico. No final do século 16 já se estimulava a ligação entre as ciências e as técnicas, assim como a aplicação prática do conhecimento matemático, químico e médico. $\mathrm{Na}$ sociedade, valorizava-se o papel da experiência adquirida em operações manuais e surgiam avanços nas artes da navegação, metalurgia, 
estamparia e outras. O desenvolvimento dessas técnicas, entretanto, estava bem distante do modelo sistematizado e controlado que caracteriza a investigação científica (HARMAN, 1995).

Outra figura que aparece no centro da mudança do paradigma científico é Galileu Galilei (1564-1642). Considerado mundialmente o fundador da física clássica, o que caracteriza sua obra, assim como a ciência moderna, é o uso do método experimental para a busca de regularidades matematicamente expressáveis na natureza - as leis naturais. Não havia espaço na universidade para as investigações mecânicas de Galileu, relacionadas à composição das máquinas e à resistência de materiais (MARICONDA, 2006). Para divulgar seu trabalho em Física e difundir o sistema heliocêntrico de Copérnico na área da Astronomia, ele escreve então suas principais obras em italiano, em vez de fazê-lo em latim, língua formal da Igreja e das universidades (SÁNCHEZ MORA, 2003).

A população da época, por sua vez, sofria com a falta de saneamento, de higiene, de tratamento adequado para doenças e estava vulnerável à fome, incêndios e perdas agrícolas. $\mathrm{Na}$ cultura popular, prevalecia a ideia de uma natureza mágica. Feiticeiros seriam capazes de ativar poderes ocultos do universo (HARMAN, 1995). Para alguns historiadores, a tradição da magia natural teve influência nas bases empíricas da nova ciência, devido ao seu aspecto naturalista e prático, caracterizado pela manipulação das chamadas qualidades ocultas, que correspondiam a processos naturais, como o magnetismo e características medicinais das plantas, ou a truques óticos com espelhos e lentes (HENRY, 1998). Esse aspecto histórico evidencia como “[...] o imaginário sociocultural de cada época [...] é a matriz epistêmica que funciona como fulcro gerador das criações do pensamento humano, condicionando as atividades da razão à estrutura inconsciente da cultura" (MORAIS, 2007, n.p.).

O pensamento de outros intelectuais do século 17, como Johann Kepler (1571-1630), Francis Bacon (1561-1626) e René Descartes (1596-1650), bem como do núcleo dominante na Royal Society de Londres, demonstrava a inserção do novo paradigma experimental no meio erudito. A influência crescente do protestantismo também é entendida como um dos fatores que possibilitaram a autonomia da ciência, em detrimento da autoridade da Igreja Católica. A revolução operada na física e na cosmologia - base dos currículos acadêmicos, à época, juntamente com a lógica e a matemática (HARMAN, 1995), conduziu a uma mudança no caráter da ciência e em seus objetivos: multiplicaram-se os centros de pesquisa empírica, afastados de investigações excessivamente abstratas e abrindo espaço apenas para as considerações teóricas verificáveis pela experiência. Essas considerações deveriam resultar na formulação de previsões, de leis naturais e de regras práticas. Um dos aspectos do novo paradigma era seu caráter mecanicista, ou seja, a visão 
da natureza não mais como um organismo vivo articulado por poderes autônomos, mas como um mecanismo regido por leis de causa e efeito (MARICONDA, 2006).

A cisão entre ciência e filosofia, cujas origens foram aqui rememoradas, constitui um dos fundamentos da ciência moderna e da ideia de objetividade científica - a noção de que ela detém uma neutralidade que a isenta de vieses, interesses, crenças e orientações de ordem social, cultural e política.

Outro aspecto essencial que caracteriza a ciência moderna é a sua associação à técnica, ou seja, a aplicação prática dos conhecimentos adquiridos na pesquisa para solução de problemas concretos, o que constitui a tecnologia.

\section{Críticas à ciência moderna: o mito da objetividade e a fragmentação do saber}

A perspectiva histórica é resgatada por Edgar Morin (2005, p. 8-9), para contestar a ideia de objetividade da ciência:

\footnotetext{
A ciência é igualmente complexa porque é inseparável de seu contexto histórico e social. A ciência moderna só pôde emergir na efervescência cultural da Renascença, na efervescência econômica, política e social do Ocidente europeu dos séculos 16 e 17. Desde então, ela se associou progressivamente à técnica, tornando-se tecnociência, e progressivamente se introduziu no coração das universidades, das sociedades, das empresas, dos Estados, transformando-os e se deixando transformar, por sua vez, pelo que ela transformava. A ciência não é científica. Sua realidade é multidimensional. [...] Assim, a ciência é, intrínseca, histórica, sociológica e eticamente, complexa. É essa complexidade específica que é preciso reconhecer.
}

Uma demonstração contundente sobre como a atividade científica pode ser negativamente influenciada por fatores sociais aparece na obra A Falsa Medida do Homem, de Stephen Jay Gould (1991). O livro ataca o determinismo biológico - corrente teórica segundo a qual padrões de comportamento e desigualdades socioeconômicas entre diferentes raças, etnias e sexos decorrem de aspectos biológicos inatos. $\mathrm{O}$ autor detém-se sobre uma série de casos de racismo científico produzidos por importantes cientistas dos séculos 19 e 20 que estimularam a classificação de indivíduos e grupos sociais de acordo com níveis de inteligência, tomando por base, por exemplo, as medidas do crânio (craniometria). Gould demonstrou a fragilidade desses estudos por meio da reanálise dos dados quantitativos primários e da revisão de seus cálculos. O autor decidiu revisar os dados originais, não apenas por estar, como pesquisador, familiarizado com essa atividade, mas também porque pretendia desmistificar um dos pilares sobre os quais o mito da objetividade científica se sustenta: as supostas evidências inquestionáveis fornecidas pelos números. Com isso, demonstrou que dados quantitativos também estão sujeitos a fraudes, erros e distorções, 
conscientes ou inconscientes, e que, nos casos citados, foram utilizados para reproduzir preconceitos sociais.

Importa, porém, destacar que o reconhecimento da subjetividade presente na atividade científica não significa a negação da realidade objetiva que a ciência investiga e descobre, como explica o próprio Gould (1991, p. 6):

\begin{abstract}
$\mathrm{Na}$ condição de cientista praticante, compartilho o credo de meus colegas: acredito que existe uma realidade concreta e que a ciência pode nos fornecer informações sobre essa realidade, embora o faça muitas vezes de maneira obtusa e irregular. Não foi durante um debate abstrato sobre o movimento lunar que mostraram a Galileu os instrumentos de tortura. As suas ideias ameaçaram o argumento convencional invocado pela Igreja para justificar a estabilidade social e doutrinária: a ordem estática do mundo, com os planetas girando em torno da Terra, os sacerdotes subordinados ao papa e os servos ao seu senhor. Mas a Igreja não tardou em fazer as pazes com a cosmologia de Galileu. Não havia outra escolha: a Terra realmente gira em torno do Sol.
\end{abstract}

A tecnociência do mundo atual, contudo, nem sempre se mostra tão autônoma, pois está frequentemente associada a interesses econômicos e políticos, que pautam as prioridades das pesquisas desde o fenômeno da industrialização global, nas décadas de 30 e 40 (SANTOS, 1988). A proliferação de armas nucleares e a degradação ambiental constituem alguns efeitos dessa subordinação.

Outra crítica tecida por Boaventura de Sousa Santos (1988) é de que a ciência moderna segue um modelo totalitário, que nega o caráter racional a outras formas de conhecimento e fecha suas portas a saberes que não se pautam por suas regras metodológicas, tais como os conhecimentos humanísticos - estudos históricos, jurídicos, filosóficos, etc. - e o conhecimento do senso comum. Para o autor, esse paradigma encontra-se em crise, pois há um movimento no interior do meio científico que tem unido conhecimentos de diferentes ramos em abordagens transdisciplinares. Pode-se citar como exemplo a Ciência do Sistema Terrestre, que envolve estudos sobre as interações de componentes do sistema natural (oceanos, solo, atmosfera, etc.) entre si ou relacionados a sistemas sociais (instituições, cultura, demografia e outros).

No paradigma emergente vislumbrado para a ciência pós-moderna existe espaço para superar a fragmentação entre Ciências Naturais, Sociais e Humanas. Nessa nova configuração, as diversas formas de conhecimento dialogam, e o maior desafio do saber científico é integrar-se ao senso comum para tornar-se acessível, transparente, prático e significativo na vida das pessoas:

$\mathrm{Na}$ ciência moderna a ruptura epistemológica simboliza o salto qualitativo do conhecimento do senso comum para o conhecimento científico; na ciência pós-moderna o salto mais importante é o que é dado do conhecimento científico para o conhecimento do senso comum. O conhecimento científico pós-moderno só se realiza enquanto tal na medida em que se converte em senso comum (SANTOS, 1988, p. 70). 
Nesse contexto inclusivo, a coletividade seria capaz de se apropriar do conhecimento compartilhado para desenvolver projetos comunitários, como erradicar uma doença ou construir um computador adaptado às suas necessidades (SANTOS, 1988).

O acesso direto ao conhecimento científico, contudo, é dificultado pela linguagem empregada no meio especializado. Ao longo do desenvolvimento da ciência, e principalmente a partir do século 20, as descrições literais da realidade foram sendo abandonadas em favor de uma linguagem simbólica e abstrata que sintetizasse o acúmulo de informações. A crescente especialização contribuiu para que cada ramo da ciência desenvolvesse seu próprio jargão, dificultando o acesso até mesmo de cientistas de outras áreas ao conhecimento produzido (SÁNCHEZ MORA, A. 2003).

Para Morin (2005), é necessário que a ciência resgate a consciência política e ética por meio da partilha do conhecimento que produz. O saber científico é decisivo para o futuro da humanidade, mas ainda permanece inatingível, afastando o cidadão comum e relegando-o à ignorância. Como peças de um quebra-cabeça, as disciplinas fragmentadas impedem a leitura abrangente do mundo até mesmo por parte dos cientistas que se especializam em determinada área, enquanto as outras lhes permanecem distantes. O conhecimento científico acaba sendo produzido para poucos e depositado em um banco de dados, quando deveria ser debatido e incorporado na vida pública.

Verifica-se que a as críticas expressas pelos autores questionam um modelo de ciência com fronteiras delimitadas por disciplinas. Esse modelo considera as pesquisas empreendidas no âmbito das ciências naturais plenamente objetivas e imunes ao arcabouço sócio-histórico-cultural do pesquisador e de sua época. Trata-se de visões que reconhecem o caráter subjetivo que condiciona essa e qualquer outra atividade humana e propõem um sistema transdisciplinar de saberes - que engloba as ciências naturais, humanas, sociais e, ainda, outros saberes empíricos - apto a analisar questões sob diferentes perspectivas. Busca-se, portanto, compor uma visão mais abrangente do mundo, com a finalidade primordial de proporcionar um futuro viável para o planeta e para a humanidade.

Ressalte-se que abrir espaço para outras formas de conhecimento não significa relativizar teorias e verdades científicas que decorram da aplicação do método sistematizado que caracteriza a investigação nas ciências naturais. Embora esteja implícito no método científico que são verdades provisórias, a superação delas está sujeita ao mesmo rigor com que foram concebidas, pois de outra maneira abre-se espaço para que qualquer afirmação obscurantista ou de caráter autoritário sobreponha-se a elas. A integração entre humanidades e ciências naturais, ao contrário, visa agregar saberes e assegurar que a ciência esteja a serviço do bem-comum.: 
A ciência pós-moderna, ao sensocomunizar-se, não despreza o conhecimento que produz tecnologia, mas entende que, tal como o conhecimento se deve traduzir em autoconhecimento, o desenvolvimento tecnológico deve traduzir-se em sabedoria de vida. É esta que assinala os marcos da prudência à nossa aventura científica. A prudência é a insegurança assumida e controlada (SANTOS, 1988, p.71).

Durante a pandemia de Covid-19, que ainda é vivenciada no momento em que este artigo é escrito, acompanharam-se pelos jornais diversas ações empreendidas em diferentes áreas do conhecimento para o enfrentamento da crise: a utilização de modelos matemáticos oriundos da astrofísica em previsões sobre o comportamento do vírus no Brasil; historiadores da Fiocruz chamados a analisar a pandemia sob o aspecto do papel do Estado, dos medos coletivos, das pandemias anteriores, dos riscos de desabastecimento e das perspectivas de ações internacionais conjuntas; o desenvolvimento de um ventilador pulmonar emergencial de baixo custo e com licença livre por engenheiros da Escola Politécnica da Universidade de São Paulo-USP; uma rede de designers, engenheiros e pesquisadores formada voluntariamente para reproduzir peças de máquinas hospitalares, por meio de tecnologia de impressão 3D; a observação empírica de profissionais na linha de frente, médicos e enfermeiros, que permitiu identificar sintomas que ainda não haviam sido documentados, como a perda de olfato e paladar, e lesões cutâneas nos pacientes. Destacou-se ainda o papel crucial da comunicação pública da ciência como instrumento de democratização das informações, evidenciado pelo constante interesse dos meios de comunicação nas explicações prestadas pela comunidade científica e pela cobertura incessante dos avanços obtidos nas pesquisas.

A articulação de conhecimentos e ações integradas entre várias áreas das ciências, das humanidades e da observação empírica oferece à sociedade mais compreensão e possibilita uma atuação mais ampla sobre a pandemia. A utilização desse corpo de conhecimentos para otimizar a gestão da crise é um importante benefício da abordagem transdisciplinar. As figuras públicas que se limitaram meramente aos aspectos microbiológicos e à relativa baixa letalidade do vírus em comparação a outros mais potentes, desconsiderando outros aspectos para além da biologia, tal como a capacidade dos sistemas de saúde de responderem à demanda provocada pelo alto nível de contágio, acabaram por apresentar uma leitura limitada - e equivocada - da situação.

\section{Pós-verdade, Comunicação da Ciência e Educação}

Segundo Viviane Mosé (2018a), a sociedade passa por uma mudança de estrutura: de um modelo piramidal, hierárquico, baseado em relações de superioridade e subordinação, para um modelo em rede, caracterizado por uma teia de conexões horizontais, proporcionadas por inovações tecnológicas como a internet, que interligam e conectam a sociedade em nível mundial. 
No passado, a verdade era ditada por quem detinha poder, e nesse novo cenário diferentes visões sobre o mesmo fato se sobrepõem, formando conteúdos dinâmicos, de maneira que a noção de 'verdade' é colocada em questão. Caracteriza-se, portanto, a pós-verdade, uma pluralidade de pontos de vista e de diferentes versões sobre a realidade. A informação não tem mais dono. Tratase de uma mudança positiva, pois vivências simultâneas a respeito de um mesmo fato podem emergir e tornar visíveis novas respostas. Entretanto, a transição de um modelo para outro faz com que a sociedade ainda não saiba lidar com seus efeitos negativos, tais como as fake news.

A noção de pós-verdade também está associada à manipulação emocional. Segundo os Oxford Dictionaries (2016), o termo refere-se a “[...] circunstâncias nas quais fatos objetivos são menos influentes na formação da opinião pública do que apelos à emoção e a crenças pessoais". Assim, a necessidade afetiva de ser aceito e reconhecido em um grupo, por exemplo, pode ser um fator que interfere no julgamento racional dos sujeitos. Assim, nem sempre a adesão a concepções errôneas e a fake news deve-se à falta de acesso à informação ou ao nível de conhecimento, mas está relacionada a crenças e valores. O sujeito escolhe acreditar nas informações que irão confirmar ou reforçar a sua visão de mundo, seu viés político e religioso e seus julgamentos morais (CASTELFRANCHI 2019). Isso denota a influência dos afetos na ordenação ética e moral dos sujeitos (MOSÉ, 2018b).

Para que a versão dos fatos apresentada pela ciência possa ser reconhecida pela população em ambientes plurais, e para que se possa fazer o contraponto a mentiras autoritárias, obscurantistas, que se fazem passar por verdade ao mobilizarem emoções, é preciso reconhecer que a afetividade é inerente aos seres humanos e envolver também essa dimensão na comunicação pública da ciência. Isso remete, novamente, à transdisciplinaridade:

\footnotetext{
A compreensão humana nos chega quando sentimos e concebemos os humanos como sujeitos; ela nos torna abertos a seus sofrimentos e suas alegrias. Permite-nos reconhecer no outro os mecanismos egocêntricos de autojustificação, que estão em nós, bem como as retroações positivas (no sentido cibernético do termo) que fazem degenerar em conflitos inexplicáveis as menores querelas. É a partir da compreensão que se pode lutar contra o ódio e a exclusão. Enfrentar a dificuldade da compreensão humana exigiria o recurso não a ensinamentos separados, mas a uma pedagogia conjunta que agrupasse filósofo, psicólogo, sociólogo, historiador, escritor, que seria conjugada a uma iniciação à lucidez (MORIN, 2003, p. 51)
}

Outro aspecto da realidade contemporânea associado à pós-verdade é o excesso de informações sem que haja estruturas teóricas prévias na mente do sujeito que lhes deem sentido. Filtrar o enorme número de informações depende de competências que possibilitem a reflexão, e quando isso não acontece, o sujeito, imerso nas notícias, acaba envolvido por uma 'nuvem de desconhecimento'. Por outro lado, o excesso de teoria, sem contato com a realidade e fechada em 
si mesma, que não propicia o debate com a realidade fática e com os contextos, também contribui para obscurecer o conhecimento (MORIN, 2005).

Para que o sujeito possa transitar pela pluralidade contemporânea com autonomia, a educação deve abrir-se para o debate, para o contraditório.

É urgente parar de pensar em linha para pensar em rede, e isso inclui aprender a ouvir, ser mais modesto, acreditar menos na verdade, abrir a questão para sempre novas interpretações, perspectivas, não ter medo de articular, aprender a retroalimentar. Em síntese, isso exige capacidade de lidar com as diferenças (MOSÉ, 2018b, n.p.).

O ensino compartimentado destrói as possibilidades de compreensão, de reflexão e de visão em longo prazo, de maneira que o indivíduo não é formado para tratar de questões multidimensionais. A transdisciplinaridade escolar deve favorecer o raciocínio multirreferencial e possibilitar a articulação de perspectivas complementares e antagônicas (MORIN, 2007).

Para ilustrar a diferença entre as perspectivas de um pensamento mais restrito e outro mais abrangente, apresenta-se a tradução de um quadro concebido por Robbins (2007) a partir de um estudo sociológico baseado em entrevistas. Esse estudo contrapôs o perfil de engenheiro tradicional com o perfil denominado 'reflexivo', correspondente a profissionais que atuavam em países em desenvolvimento, especialmente em comunidades pobres, nas áreas sanitária e de abastecimento hídrico. Esses profissionais, devido às próprias vivências, desenvolveram uma visão mais integrada e sistêmica de suas atividades e dos aspectos sociotécnicos (inter-relação de aspectos sociais e técnicos) associados a elas.

Enquanto a ideologia profissional atribuiu aos engenheiros tradicionais a capacidade de liderança decorrente do conhecimento técnico e da tomada de decisão racional, entre os engenheiros reflexivos as características que mais se destacaram são as relativas ao entendimento holístico e flexível das dinâmicas sociotécnicas: a visão do público como recurso e parceiro nos processos de tomada de decisão; a visão da educação como processo de duas vias entre os engenheiros e a comunidade; a busca de entendimento multifacetado das barreiras sociais, econômicas e ambientais para a adoção de novas tecnologias - por exemplo, verificando as causas para rejeição da comunidade a determinada tecnologia, ou se os usuários teriam condições e recursos para mantê-la (ROBBINS, 2007). 
Quadro 1 - Engenheiros tradicionais e reflexivos comparados

\begin{tabular}{|c|c|c|}
\hline & \multirow{2}{*}{ Engenheiros tradicionais } & \multirow{2}{*}{ Engenheiros reflexivos } \\
\hline & & \\
\hline $\begin{array}{l}\text { Relacionamento entre } \\
\text { tecnologia e sociedade }\end{array}$ & $\begin{array}{l}\text { Modelagem tecnológica } \mathrm{da} \\
\text { sociedade }\end{array}$ & Dinâmica sociotécnica \\
\hline $\begin{array}{c}\text { Percepção da } \\
\text { competência técnica } \\
\text { leiga }\end{array}$ & Déficit público de conhecimento & Público é um recurso de conhecimento \\
\hline $\begin{array}{l}\text { Significado de tomar } \\
\text { decisões sobre } \\
\text { tecnologia }\end{array}$ & $\begin{array}{l}\text { Especialistas engajam e educam } \\
\text { o público }\end{array}$ & $\begin{array}{l}\text { Diálogo e acordo entre público e } \\
\text { especialista }\end{array}$ \\
\hline $\begin{array}{c}\text { Visão de } \\
\text { desenvolvimento }\end{array}$ & Tecnologicamente orientado & Baseado em modos de vida* \\
\hline Aceitação tecnológica & $\begin{array}{l}\text { Especialistas comunicando-se } \\
\text { com o público geram aceitação } \\
\text { da tecnologia }\end{array}$ & $\begin{array}{l}\text { Fatores sociais, econômicos e ambientais } \\
\text { explicam por que as tecnologias são } \\
\text { adotadas ou rejeitadas }\end{array}$ \\
\hline $\begin{array}{l}\text { Política do } \\
\text { conhecimento }\end{array}$ & Engenheiros sabem mais & $\begin{array}{l}\text { Parceria entre engenheiros e partes } \\
\text { interessadas }\end{array}$ \\
\hline $\begin{array}{c}\text { Abordagem } \\
\text { epistemológica para } \\
\text { problemas e soluções }\end{array}$ & Especialização técnica & Sistemas complexos \\
\hline Visão da experiência & Estrito, baseado em disciplina & Amplo e holístico, interdisciplinar \\
\hline $\begin{array}{l}\text { Ponto de partida } \\
\text { conceitual }\end{array}$ & Projetos & Sistemas sociotécnicos \\
\hline
\end{tabular}

Fonte: ROBBINS, 2007, p. 108 (tradução nossa).

* O conceito de 'modos de vida' (livehoods) compreende as capacidades e os meios de subsistência das pessoas, incluindo alimentação, renda e bens a que têm acesso (CHAMBERS; CONWAY, 1992).

A escola pode ser uma instância que possibilita ao estudante tomar contato e apreender não apenas os conteúdos curriculares, mas também diferentes realidades, ainda que no futuro não atue diretamente com elas. A apresentação das condições sociais como obra humana, produto de relações de poder, e não como algo natural, permite ao sujeito perceber-se como força ativa em sua construção. Assim, não compete à escola apenas transmitir conceitos, mas oferecer oportunidades para que os estudantes possam elaborá-los, construí-los, relacioná-los, a fim de que analisem questões a partir de diferentes perspectivas antes de emitirem um valor. Com isso, o exercício do contraditório, o debate, a autonomia, a criatividade e o pensamento crítico são favorecidos (MOSÉ, 2019). Tais vivências contribuem para formar pessoas que utilizam a pluralidade de ideias e as diferentes realidades coexistentes para ampliar a sua leitura do mundo.

\section{Conclusão}

A questão que orientou este artigo foi a relação entre a crítica à ciência moderna e o fenômeno da pós-verdade. Nota-se, ao final, uma forte correspondência entre ambas. A noção de pós-verdade explicita o caráter multifacetado da realidade. Assim, por exemplo, uma barragem que 
se rompe e mata pessoas não é somente uma obra tecnológica mal utilizada que falhou. É também o risco estratégico assumido pela multinacional, o produto de uma fiscalização ineficiente, o sofrimento das vítimas. A crítica à fragmentação dos saberes sustenta a necessidade de um olhar mais abrangente - um conhecimento científico e também humanista -, que permita à sociedade avançar na compreensão do mundo e no entendimento mútuo.

A pós-verdade remete, ainda, à influência da subjetividade do indivíduo na sua percepção da realidade. A negação da objetividade da ciência reconhece que também a atividade científica embora capaz de descobrir aspectos concretos da realidade - não é neutra, pois condicionamentos políticos, sociais e culturais atuam sobre ela. Portanto, uma ciência com prioridades que se destinam a manter o status quo é politicamente e socialmente condicionada, assim como uma ciência comprometida com a promoção da igualdade e do bem-estar social.

O fenômeno contemporâneo da pós-verdade caracteriza-se, em síntese, como uma profusão de diferentes olhares sobre a realidade, com a emergência de perspectivas complementares e antagônicas sobre o mesmo fato. Dessa maneira, outras versões da verdade, além daquelas determinadas por poderes dominantes, passam a ser ouvidas, democratizando como nunca a comunicação entre os seres humanos. Entretanto, a outra face do fenômeno refere-se à manipulação da opinião pública por meio de narrativas falsas ou distorcidas, que recorrem a aspectos emocionais para se consolidarem como verdadeiras.

O contexto atual indica que a adoção de uma forma de pensamento que dê conta da complexidade, pluralidade, variabilidade e imprevisibilidade dos fenômenos e dos fatos é crucial para situar-se nessa nova dinâmica, quer seja no âmbito da ciência, da escola ou da sociedade. A oportunidade de integrar saberes - a transdisciplinaridade - nunca foi tão possível quanto agora, pois, por meio da internet, as pessoas encontram-se em constante conexão, e o conhecimento, muito mais acessível.

O mundo atual não oferece mais condições para que a ciência seja vista como autoridade detentora da verdade. Devido às características da comunicação em rede, hoje ela representa mais uma voz, dentre outras. Para que se constitua como força aglutinadora, deve assumir sua condição de influenciar e ser influenciada pela sociedade. Em outras palavras, reconhecer seu caráter de construção social e que, fora do campo estrito das verdades científicas, não existe neutralidade. Cabe, assim, ao meio científico participar do debate público, prestar contas à população, identificar quais interesses e valores têm orientado as pesquisas científicas, especialmente aquelas financiadas com recursos públicos e resgatar seu caráter humanista, colocando-se a serviço da coletividade. É necessário, ainda, contemplar a dimensão afetiva em sua comunicação com a sociedade. Isso significa identificar o público a que se dirige e adotar linguagem adaptada a ele, conhecer suas lutas 
e participar com a proposição de soluções para as necessidades apresentadas por diferentes grupos sociais.

Trata-se de uma tarefa destinada às instituições de ensino e pesquisa, especialmente as públicas, e aos cientistas. Ao embrenhar-se na vida pública e no debate social, o meio científico passa a ter mais subsídios para compreender as atividades que exerce e sua repercussão na comunidade, na nação e no planeta. Com isso, acumula aprendizado e ajuda a construir conhecimento contextualizado e significativo para a vida das pessoas.

Os profissionais que atuam na educação também precisam ser preparados para dar conta dessa nova configuração da sociedade em rede e proporcionar aos estudantes vivências para que possam orientar-se em ambientes plurais, utilizando a variedade de informações para compor uma visão mais abrangente do mundo.

A ciência tem como princípio a possibilidade de contestação e de refutação de suas teorias e verdades. Seu caráter, colaborativo por excelência, a leva para o lado oposto do autoritarismo. Por isso, nessa nova configuração em que a diversidade e o debate são a tônica das relações sociais, o meio científico traz em si grande experiência e potencial para agregar pessoas em torno do bem comum.

\section{Referências}

CASTELFRANCHI, Y. Divulgação Científica na Era da Informação. Campus Virtual Fiocruz, 2019. Disponível em: https://www.youtube.com/watch?v=KdErbQ1iGPc. Acesso em: 31 out. 2019.

CHAMBERS, R.; CONWAY, G. R. Sustainable rural livelihoods: practical concepts for the 21st century. IDS Discussion Paper, [s. 1.], v. 296, p. 1-29, jan. 1992.

GOULD, S. J. A Falsa Medida do Homem. São Paulo: Martins Fontes, 1991.

HARMAN, P. M. A Revolução Cientifica. São Paulo: Editora Ática, 1995.

HENRY, J. A magia e as origens da ciência moderna. In: A Revolução Cientifica e as origens da Ciência Moderna. Rio de Janeiro: Jorge Zahar Editora, 1998.

MALET, A. Divulgación y popularización científica en el siglo XVIII: Entre la apología cristiana y la propaganda ilustrada. Quark: Ciencia, medicina, comunicación y cultura, [s. 1.], n. 26, p. 13-23, 2002.

MARICONDA, P. R. Pablo Rubén. Galileu e a Ciência Moderna. Cadernos de Ciências Humanas Especiaria, [s. 1.], v. 9, n. 16, p. 267- 292, 2006.

MORAIS, R. de. Filosofia da Ciência e da Tecnologia: Introdução Metodológica e Crítica. Campinas: Papirus, 2002.

MORAIS, R. de. Ciência e Tecnologia. Campinas: Editora Alínea, 2007. 
MORIN, E. A Cabeça Bem-Feita. Rio de Janeiro: Bertrand Brasil, 2003.

MORIN, E. Ciência com Consciência. Rio de Janeiro: Bertrand Brasil, 2005.

MORIN, E. Educação e complexidade: os sete saberes e outros ensaios. São Paulo: Cortez, 2007.

MOSÉ, V. Nietzssche hoje: sobre os desafios da vida contemporânea. Petrópolis: Vozes, 2018. a.

MOSÉ, V. O contemporâneo e a Educação. 2018b. Disponível em:

https://www.youtube.com/watch?v=hyVBULSDimI. Acesso em: 23 maio. 2020.

MOSÉ, V. O poder e as redes. In: FILHO, C. de B. et al. (Orgs.). Política: Nós também sabemos fazer. Petrópolis: Vozes, 2018c.

MOSÉ, V. A espécie que sabe: do homo sapiens à crise da razão. Petrópolis: Vozes, 2019.

OXFORD DICTIONARIES. Word of the Year 2016. 2016. Disponível em:

https://languages.oup.com/word-of-the-year/2016/. Acesso em: 3 fev. 2020.

ROBBINS, P. T. The reflexive engineer: Perceptions of integrated development. Journal of International Development, [s. 1.], v. 19, n. 1, p. 99-110, 2007.

SÁNCHEZ MORA, A. M. A divulgação da ciência como literatura. Rio de Janeiro: Editora da UFRJ, 2003.

SANTOS, B. de S. Um discurso sobre as ciências na transição para uma ciência pós-moderna. Estudos Avançados, São Paulo, v. 2, n. 2, p. 46-71, mai./ago.1988. 